\title{
Bipolar Illness and Schizophrenia as Oligogenic Diseases: Implications for the Future
}

\author{
Elliot S. Gershon
}

As with most complex inheritance diseases, there are at this time no identified susceptibility genes for schizophrenia, bipolar manic-depressive illness, major depression, childhood autism, and other inherited brain disorders whose manifestations are primarily behavioral. Nonetheless, progress has occurred. Genetic epidemiologic research, based on reliable phenotypic definitions, has demonstrated the heritability of many of these disorders. Genetic linkages and associations have been reported and replicated, although there have been inconsistencies between studies, apparently due to the low statistical power of the samples studied to detect small effects genes. Nonreplications of early linkage reports in manic-depressive illness in the 1980s occurred when new cases developed in the same large families in which the linkage was originally reported, and the newly ill persons had the wrong genetic markers in the linkage region. This appears to have resulted from applying inappropriate analytic assumptions of single-gene dominant inheritance of a rare gene, which implied that new cases must arise from the same ancestral gene within the pedigree. When new cases arose in family members not sharing that chromosomal region, the initial linkage report was proved invalid. Under oligogenic inheritance, on the other hand, susceptibility genes are expected to be common, and have a substantial probability of being brought into the pedigree by persons marrying in. Nonspecific psychopathology genes may exist, shared by schizophrenia and bipolar illness, diagnoses which do not co-aggregate in families. The discovery of susceptibility mutations may be expected. Biol Psychiatry 2000;47:240-244 (C) 2000 Society of Biological Psychiatry

Key Words: Bipolar illness, schizophrenia, genetics, common disease, oligogenic, genetic counseling

\section{Introduction}

$\mathrm{C}$ ommon diseases with complex patterns of genetic transmission account for a large and disproportionate share of medical illnesses in human populations, but their

From the Department of Psychiatry, University of Chicago, Chicago, Illinois. Address reprint requests to Elliot S. Gershon, MD, Department of Psychiatry, 5841 S. Maryland Ave. MC3077, Chicago, IL 60637

Received August 2, 1999; revised October 27, 1999; accepted November 29, 1999. etiologies remain poorly characterized. Gaining some understanding of the genetic basis of these disorders is one of the foremost challenges of human genetics in the next decade. Advances that have occurred so far are, to a great extent, limited to the discovery of rare, single-gene causes of certain common disorders. Elucidation of genes contributing to a significant proportion of population susceptibility to any common disease has been slow in coming, despite some important gene discoveries, such as the association of apolipoprotein E allele 4 with the common, late-onset form of Alzheimer's disease.

Recent scientific and technological advances should enable many more susceptibility alleles to be discovered. Genetic epidemiology has served to identify familial aggregation of specific psychiatric disease phenotypes. Other advances include progress in completing the human physical gene map and genomic sequence, and the development of very high throughput genotyping, sequencing, and differential gene display systems. For recent progress in psychiatric disorders, the key developments have been statistical: conceptualization and analysis of oligogenic inheritance (inheritance due to several genes), and the development of methods of linkage analysis that do not require prior knowledge of the correct genetic model of the trait or disease (nonparametric analysis). Further progress may be confidently expected. Modest extensions of currently developed technologies, and collection of large samples of affected families, should lead to correct identification of susceptibility mutations, and from there to an understanding of the biologic basis of the common inherited psychiatric disorders.

\section{Genetic Analysis}

Historically, two paradigms of inherited disease, singlegene inheritance and what eventually became multiplegene inheritance, were developed independently (reviewed in pages 13-17 of Vogel and Motulsky 1997). It is useful to compare them (see Table 1).

For decades there was bitter controversy between the adherents of the two approaches to genetics, until Fisher, in 1918, demonstrated that the correlations between relatives on quantitative traits studied by the Galtonians can be 
Table 1. Two Historical Paradigms of Inherited Disease

\begin{tabular}{|c|c|c|}
\hline Paradigm & Mendel, 1865 & Galton, 1865 \\
\hline Model & Gene & $\begin{array}{l}\text { Heritability (not a true } \\
\text { model) }\end{array}$ \\
\hline Early analyses & $\begin{array}{l}\text { Independent segregation } \\
\text { of genes for } \\
\text { qualitative traits }\end{array}$ & $\begin{array}{l}\text { Correlation between related } \\
\text { individuals on } \\
\text { quantitative traits }\end{array}$ \\
\hline Later analyses & $\begin{array}{l}\text { Chromosomal linkage } \\
\text { (first found in fruit } \\
\text { flies; Morgan 1911, } \\
\text { Sturtevant 1913) }\end{array}$ & $\begin{array}{l}\text { Polygenic inheritance } \\
\quad \text { (Fisher, 1918) }\end{array}$ \\
\hline Successes & $\begin{array}{l}\text { Validity of "gene" } \\
\text { concept. Discoveries } \\
\text { of causative genes for } \\
\text { single-gene diseases. }\end{array}$ & $\begin{array}{l}\text { Detection of oligogenes in } \\
\text { complex traits-some } \\
\text { linkages controversial. A } \\
\text { few susceptibility genes } \\
\text { discovered. }\end{array}$ \\
\hline
\end{tabular}

modeled as the sum of effects of a very large number of individual genes with infinitesimal additive effects. This was termed polygenic inheritance, and it was not actually expected that the individual genetic components would ever be detectable. Later, it became apparent that a trait determined by a small number of genes plus environmental or random variance (oligogenic or multifactorial inheritance) could produce the same type of observable correlations in families as polygenic inheritance. It has taken most of the 20th century to progress from the discovery of chromosomal linkage for single-gene traits to successful detection by chromosomal linkage of individual genes in complex traits and diseases. Statistical analysis of schizophrenia risk in different family members and in the population has shown that oligogenic models fit the illness best. Several genes (two or three), each having a small contribution to relative risk, are the most likely inheritance pattern (Risch 1990). The same arguments would appear applicable to bipolar illness. To detect such genes, large samples of small families are the preferred type of sample (Badner et al 1998). When there is in fact oligogenic inheritance, but a large multigenerational pedigree is studied, using a model of a rare disease gene, an artefactual linkage may appear (see below).

There is a widespread perception that genetic studies of psychiatric disorders have been particularly difficult to interpret (Risch and Botstein 1996); however, results of published genome scans for a variety of complex disorders, including type 1 diabetes (Concannon et al 1998), type 2 diabetes (Hanis et al 1996) and asthma (The Collaborative Study on the Genetics of Asthma 1997) are quite similar to results of genome scans in psychiatric disorders. There are few regions providing highly significant evidence for linkage and fewer still that are replicated in multiple independent studies. Such results reflect the inherent complexity of the genetic models for these

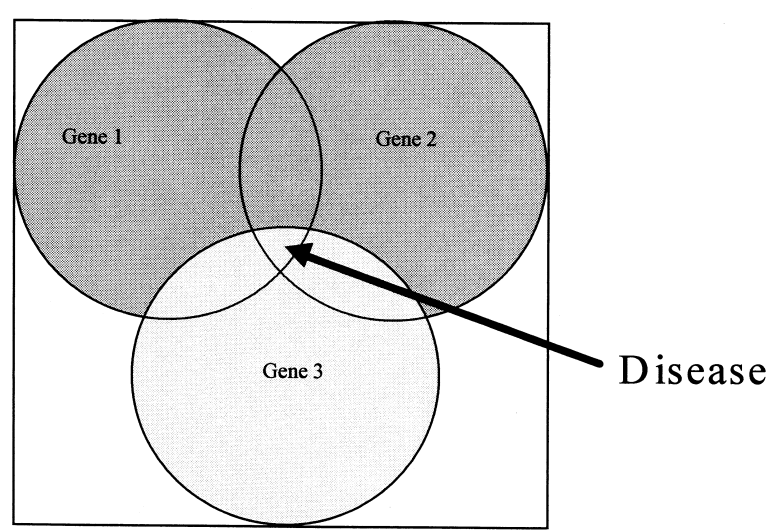

Figure 1. Oligogenic inheritance. Each circle represents the frequency of the susceptibility allele of one gene. Three genes are needed to render an individual susceptible to disease. The genes must be much more frequent than the illness.

traits (Suarez et al 1994). For the psychiatric disorders, as with most complex inheritance diseases, there are at this time no identified susceptibility genes for schizophrenia, bipolar manic-depressive illness, major depression, childhood autism, and other inherited brain disorders whose manifestations are primarily behavioral. Nonetheless, progress has occurred. Genetic epidemiologic research, based on reliable phenotypic definitions, has demonstrated the heritability of many of these disorders. Genetic linkages and associations have been reported, although there have been inconsistencies between studies, apparently due to the low statistical power of the samples studied to detect small effects genes (discussed below).

If a disease is common ( $>1 \%$ population prevalence), and results from several genes present in one individual, it followed that the genes are much more common than the disease. This conclusion, illustrated graphically in Figure 1, is widely shared (Chakravarti 1999).

Nonreplications of early linkage reports in manicdepressive illness in the 1980s occurred when new cases developed in the same large families in which the linkage was originally reported, and the newly ill persons had the wrong genetic markers in the linkage region (Kelsoe et al 1989; Baron et al 1993). This appears to have resulted from applying inappropriate analytic assumptions. That is, the assumption of single-gene dominant inheritance of a rare gene implied that new cases must arise from the same ancestral gene within the pedigree. When new cases arose in family members not sharing that chromosomal region, the initial linkage report was proved invalid. Under oligogenic inheritance, on the other hand, new cases can result from a gene (or genes) which are common, and have a substantial probability of being brought into the pedigree by persons marrying in (Badner et al 1998). 
Table 2. Statistical Power to Detect Linkage with Affected-Sib-Pairs (ASPs)

\begin{tabular}{lccc}
\hline & $\begin{array}{c}\text { Locus-specific } \\
\text { risk }\left(\lambda_{\mathrm{is}}\right)\end{array}$ & $\begin{array}{c}\text { Power to detect: } \\
100 \text { ASPs }\end{array}$ & $\begin{array}{c}\text { Power to detect: } \\
400 \text { ASPs }\end{array}$ \\
\hline Bipolar 18p (Berrettini et al 1994) & 1.6 & $5 \%$ & $59 \%$ \\
Bipolar 13q (Detera-Wadleigh et al 1999) & 1.8 & $9 \%$ & $82 \%$ \\
\hline
\end{tabular}

\section{Statistical Power to Detect Linkage}

A useful parameter for understanding common diseases is the relative risk of illness $(\lambda)$, which is the ratio of risk in a given class of relatives (usually siblings) to the population risk. In common disease, the total relative risk may be modest (10 for schizophrenia, 6 for bipolar illness) as compared with rare diseases such as Huntington's disease (relative risk greater than 10,000). The risk attributable to each of the susceptibility genes may be considerably smaller than the total risk. Table 2 has, for bipolar illness and schizophrenia, the relative risk for genes reported in recent linkage reports estimated from the raw (unpublished) data, using the method of Risch (1987) (data courtesy of SD Detera-Wadleigh, WH Berrettini, analysis courtesy of JA Badner). For each estimate of $\lambda_{\text {is }}$ (locusspecific risk to sibs), the power of different sample sizes of affected-sib-pairs (ASPs) to detect linkage with markers $10 \mathrm{cM}$ apart is given (Hauser et al 1996).

One hundred ASPs corresponds to the sample sizes available at the time the reports were published. The power to detect linkage is very modest (although under no linkage, the "power to detect" in each case was 0). The point of presenting this table is to illustrate how, even though the finding is valid, nonreplication would occur quite often under the described conditions of sample size and marker density. This does not constitute proof that the reported linkages are valid, but it does lend credence to linkages where there are conflicting reports which do not all agree. As to why there are any confirmations at all, one must bear in mind that low power is not the same as no power whatsoever.

\section{Current Linkage Findings in Bipolar Illness and Schizophrenia}

Several linkages have been reported in more than one independent sample. In the absence of an accepted metaanalysis method for linkage reports, my colleagues and I have used as a rule of thumb that a suggestive or significant linkage report (criteria of Lander and Kruglyak 1995), with at least one replication, is to be considered a viable linkage, and worthy of further research (such as searching for a mutation in the linkage region). To summarize a 1998 review (Gershon et al 1998) in bipolar illness there were independent positive reports on chromosome 18p ("p" refers to short arm, and "q" to long arm of a chromosome), 18q, 21q, and in schizophrenia on $6 \mathrm{p}$. Since preparation of that review, similar evidence has appeared for $6 \mathrm{q}$ in schizophrenia (Cao et al 1997) and also on 13q in schizophrenia (Blouin et al 1998; Lin et al 1997). Not all studies are confirmatory, and reports of other linkages have been made, but these represent the best current findings, in my opinion.

\section{Some Genes May Be Shared between Bipolar Illness and Schizophrenia}

Psychiatric geneticists have long thought of bipolar illness and schizophrenia as independent diseases, based on diagnostic genetic epidemiological findings. Neither illness is increased in families of probands with the other disorder, for example. There are arguments to the contrary; Crow (1995) recently summarized the evidence for a continuum of biologic and genetic factors in the two illnesses, arguing against the Kraeplinian dichotomy. The presence of increased morbid risk of schizoaffective disorder and of major depression in relatives of both bipolar and schizophrenia probands, for example, is inconsistent with a strict dichotomy (Gershon et al 1988).

For most researchers, however, recent reports of strongly suggestive linkage of the same markers to both bipolar illness and schizophrenia, in separate family samples, have been a great surprise. On chromosome 18p, Schwab et al (1998) have reported evidence for linkage to the same markers previously reported linked to bipolar illness (Berrettini et al 1994). On chromosome 13q32 ("32" refers to a cytogenetic segment), Detera-Wadleigh et al (1999) found evidence for linkage Bipolar illness to the same markers where others (Blouin et al 1998) had previously reported evidence for schizophrenia.

These findings have given rise to the widespread speculation that the same susceptibility genes are contributing to bipolar illness and to schizophrenia. To be consistent with the family risk data, one would postulate that the oligogenic inheritance pattern for each disease includes at least one shared gene with the other disease, but that there are also separate disease-specific genes.

\section{A Perspective on Our Contemporary Mapping Data}

At least some valid linkages to bipolar illness and schizophrenia have been found. These are frequent disease 
alleles, with an unknown range of behavioral phenotypes. Nonspecific psychopathology genes may exist, shared by diagnoses that do not co-aggregate in families. The discovery of susceptibility mutations may be expected. Once susceptibility mutations are identified, the potential applications include the following:

- Diagnostic tests of vulnerability

- New understanding of biology of susceptibility

- Treatment based on pathophysiology

- Gene therapy

These are very hopeful and ambitious predictions, but they are widely shared. It should be noted that the same biological and genetic understandings might be reached without linkage mapping at all. Candidate gene association studies (finding a gene variant which is more frequent in patients than expected), or association as a whole-genome scanning approach (Risch and Merikangas 1996), are strategies which may circumvent genetic linkage in the race toward susceptibility mutations. It appears that looking for associations with every gene in the human genome (whole-genome association) will not be an applicable strategy until after the entire human genome is sequenced, and all the common polymorphisms are known. These genetic advances are on the horizon, and may be expected within a few years.

\section{Consequences for Medicine and for Society}

Historically, visions of the future have not often been on the mark, so it is with some trepidation that I offer my expected consequences of the genetic revolution, as they may apply to human behavior and mental illnesses. Once susceptibility mutations for illness are discovered, the focus of research in these illnesses may be expected to shift from gene detection to the biological role of those genes, and to treatments based on the findings. But I would also expect a shift of research focus to the study of more subtle and complex genetic contributions to behavior (cognitive differences, personality, preferences including sexual preferences). This could generate new controversies, about performing the research and about how the findings are to be used. The development of specific "treatments" for behavioral and physical normal human variations would create its own controversies over the appropriateness of treatment. For example, would one really treat a normal personality trait or cognitive ability. Controversy over the availability of such "treatments" may also develop.

Some decades from now, one can envision molecular medicine identifying many inherited susceptibilities to common disease, diagnosable early in life. In the absence of treatment, it is difficult to know whether there is a constructive use for such knowledge; a long period of social ethical consensus-building will undoubtedly be needed to answer this question. Nonetheless, it is difficult to imagine the knowledge being technically feasible and not used, and numerous kinds of roguery could result. One can imagine stigmatization of individuals and of communities, based on genotypes (and its opposite, inappropriate enhancement of individual worth).

Unintended consequences may follow from treatments based on gene associations in complex traits. As illustrated in Figure 1, the vast majority of carriers of a common susceptibility gene for an oligogenic illness do not have the illness. The gene's more common function may be completely unrelated to illness, and could conceivably by one that greatly benefits the individual or his community. A treatment that reduces the risk of one illness might unexpectedly increase the risk of another.

New challenges in individual lives will be generated by such genetic knowledge, and will need to be dealt with. How will a person deal with his or her own genetic risks? This constitutes a class of stress unknown in previous generations, and will require that genetic counseling itself change. Where genetic counseling is now fundamentally an imparting of risk information, it will have to evolve towards psychotherapy (or psychotherapists will have to evolve towards becoming genetic counselors). It is obvious that society needs to deal with privacy and appropriate uses of genetic information, but individuals will be called upon to do the same thing. Decisions on marriage and childbearing, or adoption, for example, may become conditioned by genetic information.

These brief comments are not meant to be exhaustive, but to communicate to the reader some of the combination of excitement and dread that surrounds the current research in genetics of complex human traits and diseases. On the balance, I believe the hope of effective treatment and cures for inherited disease outweighs all the concerns, but the concerns are appropriate and must be dealt with constructively.

Aspects of this work were presented at the Janssen CNS Summit on Psychiatric Genetics, February 9, 1999, Tempe, Arizona.

\section{References}

Badner JA, Gershon ES, Goldin LR (1998): Optimal ascertainment strategies to detect linkage to common disease alleles. Am J Hum Genet 63:880-888.

Baron M, Freimer NF, Risch N, Lerer B, Alexander JR, Straub RE, et al (1993): Diminished support for linkage between manic depressive illness and X-chromosome markers in three Israeli pedigrees. Nat Genet 3:49-55.

Berrettini WH, Ferraro TN, Goldin LR, Weeks DE, DeteraWadleigh S, Nurnberger JI Jr et al (1994): Chromosome 18 
DNA markers and manic-depressive illness: Evidence for a susceptibility gene. Proc Natl Acad Sci U S A 91:5918-5921.

Blouin JL, Dombroski BA, Nath SK, Lasseter VK, Wolyniec PS, Nestadt G, et al (1998): Schizophrenia susceptibility loci on chromosomes 13q32 and 8p21. Nat Genet 20:70-73.

Cao Q, Martinez M, Zhang J, Sanders AR, Badner JA, Cravchik A, et al (1997): Suggestive evidence for a schizophrenia susceptibility locus on chromosome $6 \mathrm{q}$ and a confirmation in an independent series of pedigrees. Genomics 43:1-8.

Chakravarti A (1999): Population genetics making sense out of sequence. Nat Genet 21(Suppl):56-60.

The Collaborative Study on the Genetics of Asthma (1997): A genome-wide search for asthma susceptibility loci in ethnically diverse populations. Nat Genet 15:389-392.

Concannon P, Gogolin-Ewens KJ, Hinds DA, Wapelhorst B, Morrison VA, Stirling B, et al (1998): A second-generation screen of the human genome for susceptibility to insulindependent diabetes mellitus. Nat Genet 19:292-296.

Crow TJ (1995): A continuum of psychosis, one human gene, and not much else - the case for homogeneity. Schizophr Res 17:135-145.

Detera-Wadleigh SD, Badner JA, Berrettini WH, Yoshikawa T, Goldin LR, Turner G, et al (1999): A high-density genome scan detects evidence for a bipolar-disorder susceptibility locus on 13q32 and other potential loci on 1q32 and 18p11.2. Proc Natl Acad Sci U S A 96:5604-5609.

Gershon ES, Badner JA, Goldin LR, Sanders AR, Cravchik A, Detera-Wadleigh SD (1998): Closing in on genes for manicdepressive illness and schizophrenia. Neuropsychopharmacology 18:233-242.

Gershon ES, DeLisi LE, Hamovit J, Nurnberger JL Jr, Maxwell ME, Schreiber J, et al (1988): A controlled family study of chronic psychoses: Schizophrenia and schizoaffective disorder. Arch Gen Psychiatry 45:328-336.

Hanis CL, Boerwinkle E, Chakraborty R, Ellsworth DI, Concannon P, Stirling B, et al (1996): A genome-wide search for human non-insulin-dependent (type 2) diabetes genes reveals a major susceptibility locus on chromosome 2. Nat Genet 13:161-166.

Hauser ER, Boehnke M, Guo S-W, Risch N (1996): Affectedsib-pair interval mapping and exclusion for complex genetic traits: sampling considerations. Genet Epidemiol 13:117-137.

Kelsoe JR, Ginns EI, Egeland JA, Gerhard DS, Goldstein AM, Bale SJ, et al (1989): Re-evaluation of the linkage relationship between chromosome $11 \mathrm{p}$ loci and the gene for bipolar affective disorder in the Old Order Amish. Nature 342:238243.

Lander E, Kruglyak L (1995): Genetic dissection of complex traits: Guidelines for interpreting and reporting linkage results. Nat Genet 11:241-247.

Lin MW, Sham P, Hwu HG, Collier D, Murray R, Powell JF (1997): Suggestive evidence for linkage of schizophrenia to makers on chromosomes 13 in Caucasian but not Oriental populations. Hum Genet 99:417-420.

Risch N (1987): Assessing the role of HLA-linked and unlinked determinants of disease. Am J Hum Genet 40:1-14.

Risch N (1990): Linkage strategies for genetically complex traits. I. Multilocus models. Am J Hum Genet 46:222-228.

Risch N, Botstein D (1996): A manic depressive history. Nat Genet 12:351-353.

Risch N, Merikangas K (1996): The future of genetics studies of complex human diseases. Science 273:1516-1517.

Schwab SG, Hallmayer J, Lerer B, Albus M, Borrmann M, Honig S, et al (1998): Support for a chromosome 18p locus conferring susceptibility to functional psychoses in families with schizophrenia, by association and linkage analysis. Am J Hum Genet 63:1139-1152.

Suarez BK, Hampe CL, VanEerdewegh PV (1994): Problems of replicating linkage claims in psychiatry. In: Gershon ES, Cloniger CR (editors). Genetic Approaches to Mental Disorders. Washington DC: American Psychiatric Press, 23-46.

Vogel F, Motulsky A (1997): Human Genetics: Problems and Approaches. Berlin: Springer. 